\title{
CREB (CAMP Response Element-Binding Protein) in the Locus Coeruleus: Biochemical, Physiological, and Behavioral Evidence for a Role in Opiate Dependence
}

\author{
Sarah B. Lane-Ladd, ${ }^{1}$ Joseba Pineda, ${ }^{1}$ Virginia A. Boundy, ${ }^{1}$ T. Pfeuffer, ${ }^{2}$ John Krupinski, ${ }^{3}$ \\ George K. Aghajanian, ${ }^{1}$ and Eric J. Nestler ${ }^{1}$ \\ ${ }^{1}$ Laboratory of Molecular Psychiatry, Departments of Psychiatry and Pharmacology, Yale University School of Medicine \\ and Connecticut Mental Health Center, New Haven, Connecticut 06508, 2Institut fur Physiologische Chemie II, Dusseldorf \\ D-40225, Germany, and 3Bristol-Myers Squibb Research Institute, Princeton, New Jersey 08543
}

\begin{abstract}
Chronic morphine administration increases levels of adenylyl cyclase and CAMP-dependent protein kinase (PKA) activity in the locus coeruleus (LC), which contributes to the severalfold activation of $L C$ neurons that occurs during opiate withdrawal. A role for the transcription factor CAMP response elementbinding protein (CREB) in mediating the opiate-induced upregulation of the CAMP pathway has been suggested, but direct evidence is lacking. In the present study, we first demonstrated that the morphine-induced increases in adenylyl cyclase and PKA activity in the LC are associated with selective increases in levels of immunoreactivity of types I and VIII adenylyl cyclase and of the catalytic and type II regulatory subunits of PKA. We next used antisense oligonucleotides directed against CREB to study the role of this transcription factor in mediating these effects. Infusion (5 d) of CREB antisense oligonucleotide directly into the LC significantly reduced levels of CREB immunoreactivity. This effect was sequence-specific and not associated with detectable toxicity. CREB antisense oligonucleotide infusions completely blocked the morphine-induced upregula-
\end{abstract}

tion of type VIII adenylyl cyclase but not of PKA. The infusions also blocked the morphine-induced upregulation of tyrosine hydroxylase but not of Gi $\alpha$, two other proteins induced in the LC by chronic morphine treatment. Electrophysiological studies revealed that intra-LC antisense oligonucleotide infusions completely prevented the morphine-induced increase in spontaneous firing rates of $L C$ neurons in brain slices. This blockade was completely reversed by addition of 8-bromo-cAMP (which activates PKA) but not by addition of forskolin (which activates adenylyl cyclase). Intra-LC infusions of CREB antisense oligonucleotide also reduced the development of physical dependence to opiates, based on attenuation of opiate withdrawal. Together, these findings provide the first direct evidence that CREB mediates the morphine-induced upregulation of specific components of the CAMP pathway in the LC that contribute to physical opiate dependence.

Key words: morphine; opiate withdrawal; gene expression; cAMP; adenylyl cyclase; protein kinase A; G-proteins; tyrosine hydroxylase; protein phosphorylation
The locus coeruleus (LC) has served as a useful model system in which to study the long-term actions of opiates on target neurons. The LC is the major noradrenergic nucleus in brain, located on the floor of the fourth ventricle in the anterior pons (Dahlstrom and Fuxe, 1965; Foote et al., 1983; Aston-Jones et al., 1996). Under normal conditions, the LC is implicated in controlling attention, vigilance, and activity of the autonomic nervous system. The LC also has been implicated in physical opiate dependence. Whereas acute opiate administration inhibits the activity of LC neurons, their firing rates recover toward control levels after chronic exposure and increase more than fourfold above control levels on administration of an opioid receptor antagonist in vivo (Aghajanian, 1978; Rasmussen and Aghajanian, 1989; Rasmussen

\footnotetext{
Received May 27, 1997; revised July 18, 1997; accepted July 25, 1997.

This work was supported by the National Institute on Drug Abuse DA08227 and DA00203 and by the Abraham Ribicoff Research Facilities of the Connecticut Mental Health Center, State of Connecticut Department of Mental Health and Addiction Services. J.P. was a recipient of a fellowship from the Basque Government.

Correspondence should be addressed to Eric J. Nestler, Laboratory of Molecular Psychiatry, Departments of Psychiatry and Pharmacology, Yale University School of Medicine and Connecticut Mental Health Center, 34 Park Street, New Haven, CT 06508.

Dr. Pineda's present address: Department of Pharmacology, Faculty of Medicine, University of the Basque Country, E-48940, Leioa, Bizkaia, Spain.

Copyright (C) 1997 Society for Neuroscience $0270-6474 / 97 / 177890-12 \$ 05.00 / 0$
}

et al., 1990; Akaoka and Aston-Jones, 1991). Several studies provide direct evidence that this activation of the LC contributes to many of the behavioral signs and symptoms of physical opiate withdrawal (Rasmussen et al., 1990; Koob et al., 1992; Maldonado and Koob, 1993; for an opposing view, see Christie et al., 1997).

The activation of the LC that occurs during opiate withdrawal appears to be mediated in part by upregulation of the cAMP pathway elicited by chronic morphine administration. Thus, chronic morphine treatment increases levels of adenylyl cyclase and cAMP-dependent protein kinase (PKA) in the LC (Duman et al., 1988; Nestler and Tallman, 1988; Matsuoka et al., 1994). This upregulation has been shown in vitro to increase the tonic pacemaker activity of LC neurons (Kogan et al., 1992), possibly via activation of a sodium-dependent inward current (Alreja and Aghajanian, 1993). This action could contribute to tolerance by returning LC firing rates toward control levels during a course of chronic morphine treatment. On administration of an opiate receptor antagonist, and the removal of the inhibitory effect of morphine on the neurons, upregulation of the cAMP pathway could contribute to the dramatic activation of LC neurons seen during withdrawal. This scheme is supported by several lines of evidence (Nestler, 1992, 1996), most recently by the findings that intra-LC administration of PKA inhibitors attenuates opiate withdrawal, whereas administration of PKA activators worsens 
withdrawal and can even elicit withdrawal-like behaviors in opiate-naive animals (Maldonado et al., 1995; Punch et al., 1997).

The mechanism by which chronic morphine administration upregulates components of the cAMP pathway remains unknown. A role for alterations in gene expression has been proposed (Nestler et al., 1993; Nestler, 1996), based on the observation that the expression and phosphorylation of the cAMPregulated transcription factor cAMP response element-binding protein (CREB) are selectively upregulated in the LC after chronic morphine treatment (Guitart et al., 1992; Widnell et al., 1994). Support for this scheme comes from recent studies of mice deficient in CREB, which exhibit attenuated opiate dependence and withdrawal compared with wild-type mice (Maldonado et al., 1996). However, these studies do not specifically implicate the LC, because the CREB mutant mice are deficient in CREB in all brain regions. Moreover, the studies do not provide information concerning specific target genes through which CREB might produce these effects.

In the present study, we used antisense oligonucleotides directed against CREB (Widnell et al., 1996a) to study more directly the role of this transcription factor in mediating the longterm effects of chronic morphine in the LC. Based on biochemical, electrophysiological, and behavioral experiments, we provide here direct evidence that CREB does mediate the morphine-induced upregulation of particular components of the cAMP pathway in the LC that contributes to physical opiate dependence and withdrawal. A preliminary report of these findings has appeared (Lane et al., 1996).

\section{MATERIALS AND METHODS}

Drug treatments. Male Sprague Dawley rats (initial weight $\sim 260 \mathrm{gm}$ ) obtained from CAMM (Wayne, NJ) were used in these studies. Chronic morphine treatment involved the subcutaneous implantation of pellets (containing $75 \mathrm{mg}$ of morphine base; National Institute on Drug Abuse) daily for $5 \mathrm{~d}$ (unless otherwise specified) under light halothane anesthesia. Rats were used $18 \mathrm{hr}$ after the last pellet implantation. Control rats received sham surgery. This protocol has been shown to result in high levels of opiate dependence based on biochemical and electrophysiological findings in the LC as well as behavioral studies of opiate withdrawal (Guitart and Nestler, 1989; Rasmussen et al., 1990). Opiate withdrawal was precipitated in morphine-treated rats by subcutaneous administration of naltrexone hydrochloride (Sigma, St. Louis, MO), $10 \mathrm{mg} / \mathrm{kg}$ in $0.9 \% \mathrm{NaCl}$. This dose of naltrexone has been shown to result in maximal levels of withdrawal for at least a $1 \mathrm{hr}$ period (Rasmussen et al., 1990). Acute morphine treatment involved the subcutaneous administration of morphine sulfate $(10 \mathrm{mg} / \mathrm{kg}$; National Institute on Drug Abuse), with rats used 45 min later, the time of maximal behavioral effects of the drug (see Nestler and Tallman, 1988).

Intra- $L C$ infusions of CREB antisense oligonucleotide. Selective reductions in CREB levels in the LC were achieved by use of an antisense oligonucleotide strategy based on a recently published procedure (Widnell et al., 1996a). Briefly, oligonucleotides were infused into the lateral boundary of the LC by osmotic minipumps. We used oligonucleotides that were phosphorothioate-modified only on the terminal base pairs, because these have been shown to produce sequence-specific effects without detectable toxicity in other brain regions (Widnell et al., 1996a). The following oligonucleotide sequences were used: CREB antisense, 5'TGGTCATCTAGTCACCGGTG3'; CREB sense, 5'CACCGGTGACTAGATGACCA3'; and CREB missense, 5'GACCTCAGGTAGTCGTCGTT3' (Midland Certified Reagent Co., Midland, TX). The antisense sequence was directed at the translation start site of CREB mRNA and was chosen based on its published efficacy in reducing CREB immunoreactivity in striatum and nucleus accumbens (Konradi et al., 1994; Widnell et al., 1996a). Before administration to the animals, the oligonucleotides were ethanol-precipitated, washed three times with $70 \%$ ethanol, and resuspended in sterile PBS. The concentration of oligonucleotide was determined by optical density. Rats were anesthetized with an intraperitoneal injection of pentobarbital $(50 \mathrm{mg} / \mathrm{kg}$; Abbott, North Chicago, IL). The animals were then surgically implanted with a 28 gauge unilateral osmotic minipump cannula with the following stereotaxic coordinates: $-1.1 \mathrm{~mm}$ anterior to bregma, $1.1 \mathrm{~mm}$ lateral from midline, and $6.5 \mathrm{~mm}$ ventral to dura (Paxinos and Watson, 1982). Osmotic minipumps (Alzet 1007D; Alza, Palo Alto, CA) were used to deliver continuous infusions of oligonucleotide $(20 \mu \mathrm{g} / \mathrm{d})$ into the $\mathrm{LC}$ at a rate of $0.5 \mu \mathrm{l} / \mathrm{hr}$; the contralateral LC received no treatment. Before implantation, the minipumps were filled, and a $2.5 \mathrm{~cm}$ length of polyethylene tubing (PE-60; Clay Adams) was connected to the minipump flow moderator and sealed with LocTite glue (Bearing Distributors). The minipumps were primed by submersion in sterile saline at $37^{\circ} \mathrm{C}$ overnight. Immediately after cannula implantation, a minipump containing oligonucleotide was attached to the minipump cannula via the PE tubing and sealed with LocTite. The minipump and tubing were implanted subcutaneously between the animal's scapulae. Rats were killed $5 \mathrm{~d}$ after minipump implantation. In some experiments ["antisense (AS) reversal"], pumps containing antisense oligonucleotide were switched after $5 \mathrm{~d}$ with pumps containing the PBS vehicle, and the rats were killed $5 \mathrm{~d}$ later.

In all experiments, levels of immunoreactivity of a protein on the oligonucleotide-infused side were compared with the immunoreactivity on the contralateral, uninf used side. This enabled a within-animal comparison, as opposed to a between-animal comparison, which reduced variability in the data. In all experiments, treated versus control samples were compared using Student's $t$ test.

In some experiments, the integrity of the brain tissue around the site of oligonucleotide infusion was studied by standard histological techniques. Rats were perfused with saline followed by paraformaldehyde, and $40-\mu \mathrm{m}$-thick coronal sections were obtained from fixed brains through the LC. Sections were analyzed by immunohistochemistry for tyrosine hydroxylase exactly as described (Berhow et al., 1996) or by cresyl violet staining.

Brain dissections. Brains were removed rapidly from decapitated rats and cooled in ice-cold physiological buffer (see Nestler and Tallman, 1988). Individual LC nuclei were obtained as 14 gauge punches from 0.8 to 1-mm-thick coronal sections of brainstem as described (Nestler and Tallman, 1988). In the antisense oligonucleotide experiments, each individual LC punch (containing $0.5-0.7 \mathrm{mg}$ of wet weight tissue) was analyzed separately, with the infused LC compared with its contralateral control. In some experiments, a donut-shaped ring of tissue was obtained with a 12 gauge punch immediately outside the LC dissection.

In early experiments examining the regional distribution of adenylyl cyclase subtypes, additional brain regions were dissected. LC, dorsal raphe (including adjacent periaqueductal gray), substantia nigra, ventral tegmental area, nucleus accumbens, and prefrontal cortex were obtained as 15-12 gauge punches as described (see Fitzgerald et al., 1996). Parietal cortex, hippocampus, caudate-putamen, thalamus, hypothalamus, midbrain, anterior pons (at the level of LC), cerebellum, and spinal cord were obtained by gross dissection.

Western blotting. In most experiments, brain samples were homogenized $(10 \mathrm{mg}$ of wet weight $/ \mathrm{ml})$ in $1 \%$ SDS. For analysis of CREB, brain samples were homogenized in a high-detergent buffer to maximize extraction of this protein (see Widnell et al., 1996a). Protein content was determined by the Bradford method. Aliquots of crude extracts (containing 5-50 $\mu \mathrm{g}$ of protein) were then subjected to SDS-polyacrylamide gel electrophoresis, with resolving gels containing 6-8\% acrylamide $(30: 1.2$ ratio of acrylamide to bisacrylamide). Proteins in resulting gels were transferred electrophoretically to nitrocellulose filters, which were then analyzed by Western blotting as described (Fitzgerald et al., 1996). Briefly, filters were washed for $2 \mathrm{hr}$ at room temperature in blotting buffer $\left(125 \mathrm{~mm} \mathrm{NaCl}, \mathrm{NaPO}_{4}, \mathrm{pH} 7.4,0.05 \%\right.$ Tween, and $0.5 \%$ nonfat dry milk), incubated with primary antibody overnight at $4^{\circ} \mathrm{C}$, washed in blotting buffer for 3-4 $\mathrm{hr}$ at room temperature with five changes, incubated in peroxidase-conjugated secondary antibody (1:2,000; Vector Laboratories, Burlingame, $\mathrm{CA}$ ) for $1.5 \mathrm{hr}$ at room temperature, and finally washed for $3 \mathrm{hr}$ in blotting buffer at room temperature with five changes. Filters were developed with the enhanced chemiluminescence method of Amersham (Arlington Heights, IL) and exposed to Hyperfilm (Amersham).

The following rabbit polyclonal anti-adenylyl cyclase antibodies were used: anti-adenylyl cyclase type I (1:1000; from T. Pfeuffer); anti-adenylyl cyclase type II (1:2000; from Santa Cruz Biotechnology, Santa Cruz, CA); anti-adenylyl cyclase type III (1:2000; from Santa Cruz Biotechnology); anti-adenylyl cyclase type IV (1:1000; from Santa Cruz); antiadenylyl cyclase type V (1:1000) (Wallach et al., 1994); and anti-adenylyl cyclase type VIII (1:250) (Cali et al., 1996). For PKA, the following rabbit polyclonal antibodies were used: anti-catalytic subunit (1:1000; 
provided by C. Rubin, Albert Einstein College of Medicine and Santa Cruz Biotechnology); anti-regulatory subunit type I (1:1000; from Transduction Laboratories, Lexington, KY); and anti-regulatory subunit type II (1:1000; from Santa Cruz Biotechnology). Results with these antibodies were confirmed with a second set of antibodies for the catalytic subunit (provided by M. Uhler, University of Michigan) and for the type I and type II regulatory subunits (provided by S. Shenolikar, Duke University). The specificity of each of these antibodies was demonstrated by the recognition of bands at the expected $\mathrm{M}_{\mathrm{r}}$ and the selective obliteration of these bands by preincubation of the antibody with the respective immunizing peptide. Other antibodies were used as described previously: anti-CREB (1:20,000; provided by D. Ginty, Johns Hopkins University); anti-tyrosine hydroxylase (1:10,000; provided by J. Haycock, Louisiana State University); and anti-Gi $\alpha 1 / 2$ (1:10,000; obtained from DuPont NEN, Wilmington, DE). The specificity of these antibodies has been established (Guitart et al., 1990; Nestler et al., 1990; Widnell et al., 1994).

Levels of immunoreactivity were quantified with an Apple Macintoshbased image analysis system. Equal loading and transfer of proteins was confirmed in every experiment by analyzing resulting blots with amido black staining. For the chronic morphine and antisense oligonucleotide studies, the Western blotting conditions used were shown to result in levels of immunoreactivity of each of the proteins studied that were linear over at least a threefold range of LC concentration. Levels of the proteins in experimental samples were compared with those in matched controls; statistical analyses were performed on these percentage of control values.

Electrophysiological recordings from LC neurons. Brain slices were prepared as described previously (Kogan et al., 1992) using a vibrating knife microtome (Vibraslice, WPI). Slices containing the LC were transferred onto the stage of a gas-liquid interface brain slice chamber in which a constant flow of humidified $95 \% \mathrm{O}_{2}: 5 \% \mathrm{CO}_{2}$ and physiological buffer ( $1 \mathrm{mg} / \mathrm{min}$ ) (in mM: $126 \mathrm{NaCl}, 3 \mathrm{KCl}, 2 \mathrm{CaCl}_{2}, 2 \mathrm{MgSO}_{4}, 26$ $\mathrm{NaHCO}_{3}, 1.25 \mathrm{NaH}_{2} \mathrm{PO}_{4}$, and 10 D-glucose, $\mathrm{pH}$ 7.34) was maintained throughout the experiment at $33^{\circ} \mathrm{C}$. Single-unit extracellular potentials were recorded by the use of glass microelectrodes filled with $2 \mathrm{M} \mathrm{NaCl}$ (1-5 M $\Omega$ ) and monitored through a high-input impedance amplifier. The LCs were visually identified. All cells recorded in this study displayed triphasic waveforms (positive, negative, positive), regular rhythms, and slow spontaneous firing rates. Consecutive cells were sampled by multiple electrode tracts randomly positioned within the LC and recorded for a minimum of 3-5 min to ensure that the firing rates were stable. Firing rates of LC neurons were also recorded after bath application (for at least $10 \mathrm{~min})$ of 8-bromo-cAMP $(2 \mathrm{mM})$ or forskolin $(10 \mu \mathrm{M})$, concentrations known to elicit maximal electrophysiological responses in LC neurons (Kogan et al., 1992). Typically, as many as eight cells could be sampled per hour under both basal and stimulated conditions. For each brain slice, recordings were obtained from neurons in the oligonucleotideinfused LC and in the contralateral uninfused LC. For statistical analysis, the firing rates of neurons (typically $8-10$ ) from a single LC were averaged and considered as a single data point. Firing rates from the infused LCs were compared with those of the contralateral, uninfused LCs by paired $t$ tests.

In these studies, rats underwent intracranial surgery for initiation of antisense or sense oligonucleotide infusions on day 1, were implanted with morphine pellets on days $2-5$, and were used for electrophysiological experiments on day 6 . We used rats that had received $4 \mathrm{~d}$ of morphine pellet implantations so that results from these experiments could be compared with our earlier investigations (Kogan et al., 1992). LC neurons were recorded at least $2 \mathrm{hr}$ after preparation of the brain slice to allow morphine to wash out (Kogan et al., 1992).

Behavioral assessment of opiate withdrawal. Opiate withdrawal behaviors were assessed as described previously (Rasmussen et al., 1990; Guitart et al., 1993). Briefly, rats were placed in plastic caging $(14 \times 8 \times$ 6 inches) with clean bedding $1 \mathrm{hr}$ before precipitation of withdrawal. Withdrawal behaviors were monitored by a blind observer in $15 \mathrm{~min}$ epochs, beginning $15 \mathrm{~min}$ before, until $1 \mathrm{hr}$ after, naltrexone administration (see above). The absolute frequency of four episodic behaviors was recorded, and an additional score was calculated based on multiples of five incidents ( 0 , no incidents; 1, 1-5 incidents; 2, 6-10 incidents; and 3, 11 or more incidents). Behaviors scored in this manner included wet dog shakes, teeth chatter, vacuous chewing, and stereotypical movements. Six other behaviors, which could not be defined in discrete episodes, were assessed using predefined anchor points on a four-point scale: 0 , absent; 1 , mild; 2, moderate; and 3, marked. Behaviors scored in this manner included ptosis, lacrimation, salivation, piloerection, irritability, and diarrhea. The weights of the animals, $1 \mathrm{hr}$ before and after precipitation of withdrawal, were also obtained. In these behavioral experiments, rats underwent intracranial surgery for initiation of antisense oligonucleotide infusions on day 1 , were implanted with morphine pellets on days 2 and 3 , and were studied for withdrawal on day 6 . The use of a smaller number of morphine pellets results in animals that are less sick during withdrawal and thereby exhibit a broader range of opiate withdrawal behaviors.

\section{RESULTS}

\section{Regional distribution of adenylyl cyclase subtypes in rat brain}

In an earlier study, chronic morphine treatment was shown to increase levels of adenylyl cyclase catalytic activity in the LC (Duman et al., 1988). However, it has remained unknown which of the nine known forms of the enzyme is responsible for this increase. Levels of mRNA of the type VIII enzyme have been shown by in situ hybridization to increase in the LC after chronic morphine treatment (Matzuoka et al., 1994), but other forms have not been examined. Moreover, although the expression of some forms of adenylyl cyclase in select brain regions has been studied at the mRNA level by in situ hybridization (e.g., Xia et al., 1993; Cali et al., 1994; Cooper et al., 1995; Hellevuo et al., 1995; Sunahara et al., 1995), there has not been a systematic survey of the distributions of these various enzymes in the brain. Therefore, as a first step in studying a role for CREB in mediating the morphine-induced upregulation of adenylyl cyclase in the LC, we performed a regional analysis to identify forms of the enzyme that are expressed in this brain region.

As shown in Figure 1, we examined the distribution of types I, II, III, IV, V, and V III adenylyl cyclase by Western blotting. (We did not study types VI, VII, and IX, because specific antibodies were not available.) In each case, the antibodies used recognized a protein of the correct $\mathrm{M}_{\mathrm{r}}$, which was abolished by preabsorbing the antibody with its specific antigen (see Materials and Methods). Some of the antibodies specifically recognized relatively broad bands or even more than one band (for example, types III and VIII adenylyl cyclase); this has been shown to be attributable to splice variants and post-translational modifications of the enzymes (e.g., Cali et al., 1996); interestingly, we observed regional differences in the relative levels of these bands. Types I, II, III, IV, and VIII adenylyl cyclase showed a widespread distribution in brain. Type VIII adenylyl cyclase was unique in that relative levels of this subtype in the LC were among the highest throughout brain, whereas relative levels of the other subtypes were generally lower in the LC compared with many other brain regions. In fact, the type II enzyme was not even detectable in the LC, which was unexpected given a previous report of appreciable levels of type II mRNA in this brain region (Furuyama et al., 1993). Type V adenylyl cyclase was highly enriched in caudateputamen, nucleus accumbens, and substantia nigra, as reported previously (Glatt and Snyder, 1993), although the enzyme is present throughout the brain, albeit at much lower levels.

\section{Regulation of adenylyl cyclase and PKA immunoreactivity in the LC by chronic morphine administration}

To determine whether the observed morphine-induced increase in adenylyl cyclase activity (Duman et al., 1988) is associated with increased expression of the enzyme, and to determine which enzyme subtype is regulated, we next examined the effect of chronic morphine administration on levels of the several subtypes of adenylyl cyclase found to be expressed in the LC. As shown in Table 1, levels of the type VIII and type I enzymes were selec- 

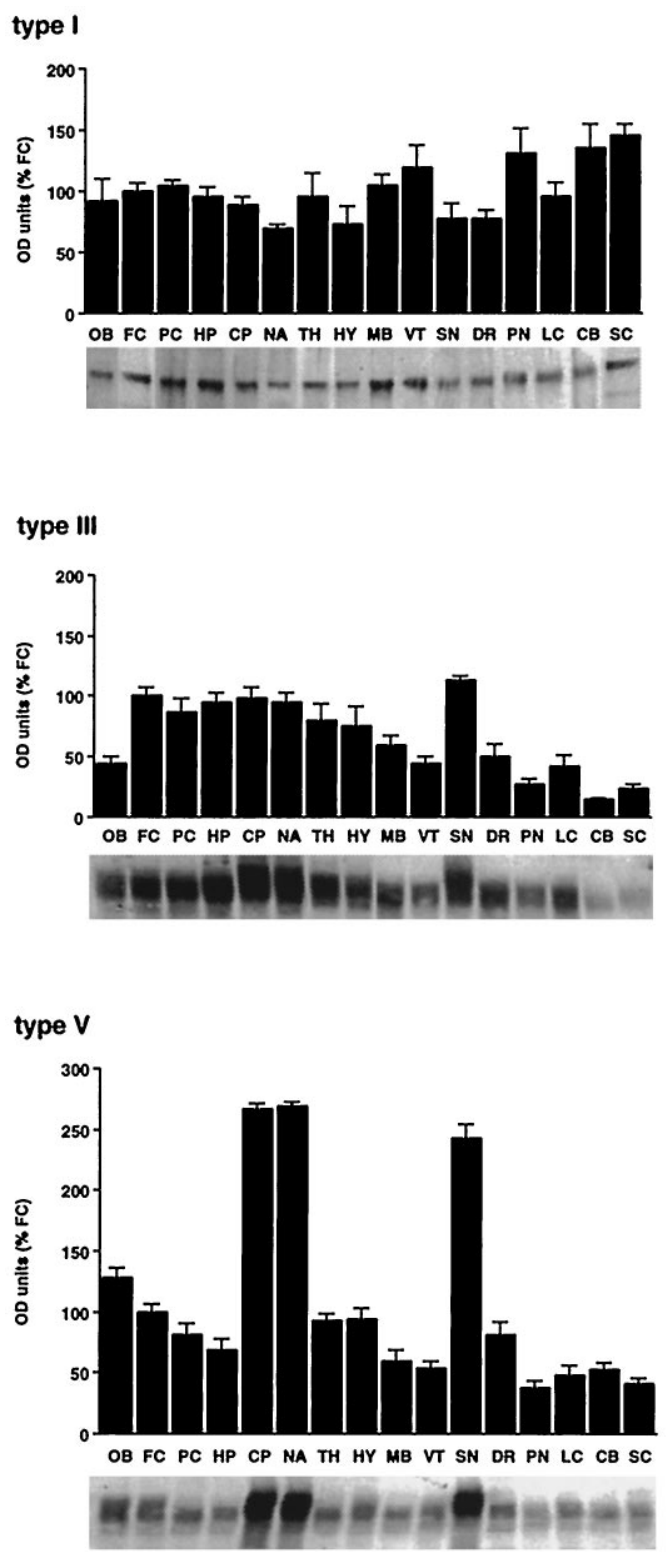
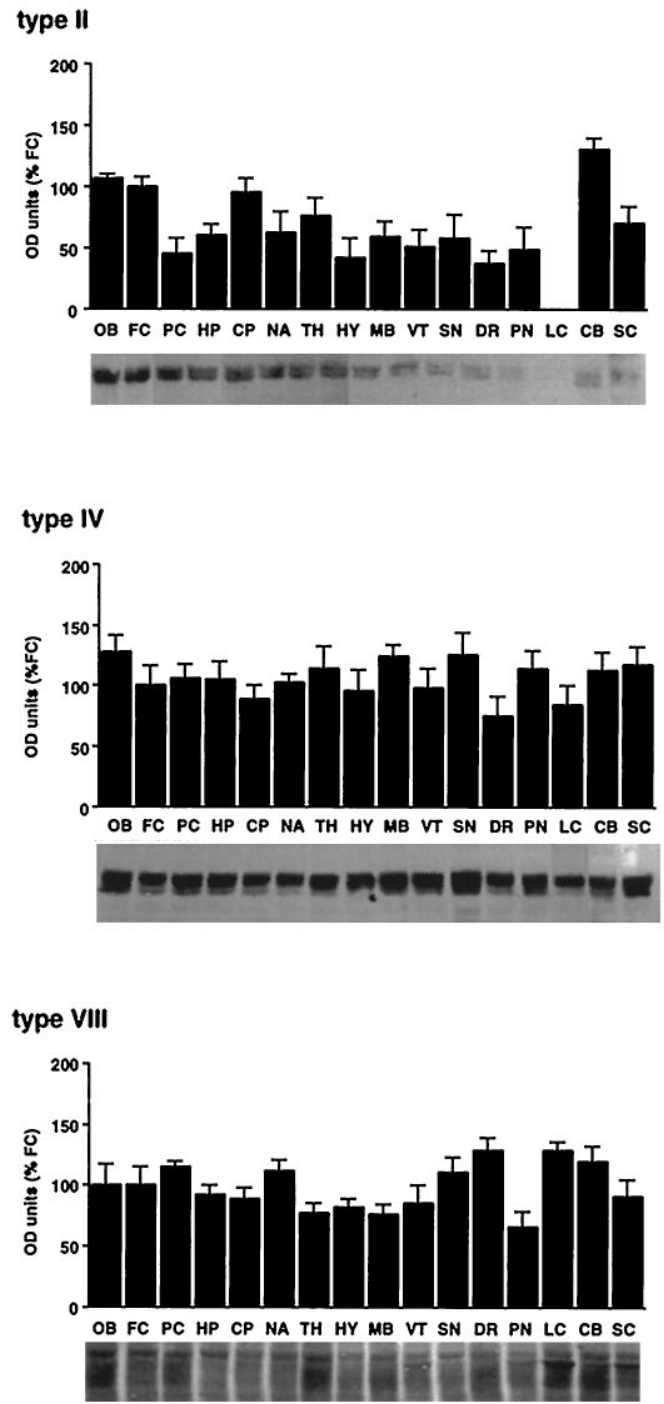

Figure 1. Regional distribution of adenylyl cyclases in brain. Extracts of brain regions were analyzed for types I, II, III, IV, V, and V III adenylyl cyclase immunoreactivity by Western blotting using type-specific antibodies (see Materials and Methods). The $\mathrm{M}_{\mathrm{r}}$ values observed for these enzymes were type I, $135 \mathrm{kDa}$; type II, $115 \mathrm{kDa}$; type III, $130 \mathrm{kDa}$; type IV, $120 \mathrm{kDa}$; type V, $125 \mathrm{kDa}$; and type VIII, $165 \mathrm{kDa}$, which are consistent with published values (Cooper et al., 1995; Sunahara et al., 1995). Data are expressed as mean \pm SEM $(n=4)$ relative to values (arbitrarily set at 100$)$ in frontal cortex. $O B$, Olfactory bulb; $F C$, frontal cortex; $P C$, parietal cortex; $H P$, hippocampus; $C P$, caudate-putamen; $N A$, nucleus accumbens; $T H$, thalamus; $H Y$, hypothalamus; $M B$, midbrain; $V T$, ventral tegmental area; $S N$, substantia area; $D R$, dorsal raphe (which also includes ventral periaqueductal gray); $P N$, pons; $L C$, locus coeruleus; $C B$, cerebellum; $S C$, spinal cord.

tively increased by morphine administration in this brain region. This effect required chronic exposure to morphine, because acute morphine administration had no effect (data not shown).

As with adenylyl cyclase, our earlier study of morphine regulation of PKA in the LC demonstrated an increase in levels of PKA catalytic activity (Nestler and Tallman, 1988). To determine whether this increase in PKA activity was associated with increased expression of the enzyme, we examined levels of PKA subunits in the LC under control and morphine-treated conditions. As shown in Table 1 and Figure 2, chronic morphine treatment increased levels of the catalytic subunit, as well as levels of the type II regulatory subunit, of PKA. In contrast, levels of the type I regulatory subunit were unaltered by morphine expo- sure. These effects of morphine on the catalytic and type II regulatory subunits, and the lack of effect on the type I regulatory subunit, were confirmed with a second series of antibodies (data not shown). In contrast to chronic morphine treatment, acute administration of the drug did not alter levels of immunoreactivity of the catalytic or type I or II regulatory subunit in the LC (data not shown).

\section{Establishment of an antisense oligonucleotide method to reduce levels of CREB in the LC}

In a previous study, we developed a procedure to produce a sustained decrease in levels of CREB expression in the nucleus accumbens by continuous infusion of an antisense oligonucleo- 


\begin{tabular}{lc}
\hline $\begin{array}{l}\text { Table 1. Regulation of cAMP pathway proteins in the LC by chronic } \\
\text { morphine administration }\end{array}$ & Protein immunoreactivity \\
& \\
\hline Adenylyl cyclase & $126 \pm 6(19)^{*}$ \\
Type I & $89 \pm 5(6)$ \\
Type III & $104 \pm 4(6)$ \\
Type IV & $93 \pm 3(6)$ \\
Type V & $124 \pm 7(12)^{*}$ \\
Type V III & \\
Protein kinase A & $141 \pm 7(12)^{*}$ \\
Catalytic subunit & $104 \pm 9(12)$ \\
Regulatory subunit type I & $133 \pm 6(12)^{*}$ \\
Regulatory subunit type II & $134 \pm 7(6)^{*}$ \\
Gi $\alpha$ & $153 \pm 8(6)^{*}$ \\
Tyrosine hydroxylase & $142 \pm 9(6)^{*}$ \\
CREB &
\end{tabular}

$\overline{\text { Data are expressed as mean } \pm \text { SEM percent of control }(n) \text {. Results on tyrosine }}$ hydroxylase and CREB represent replications of published findings (Guitart et al., 1990; Widnell et al., 1994).

$* p<0.05$ by $t$ test.
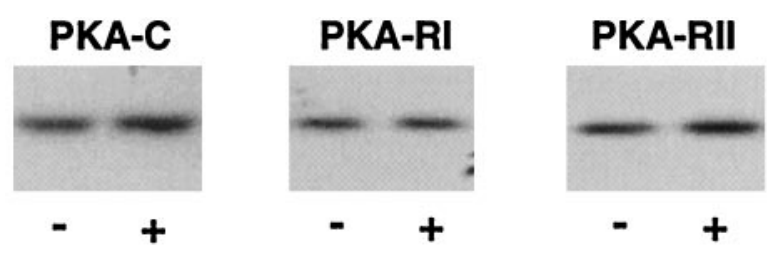

TH

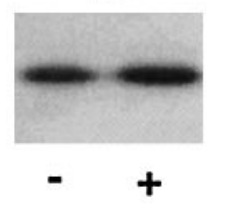

Gi $\alpha$

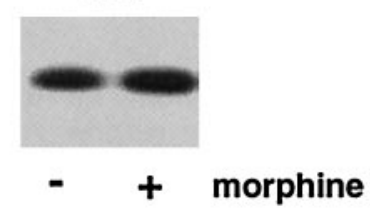

Figure 2. Autoradiograms showing regulation of PKA subunits, Gi $\alpha$, and tyrosine hydroxylase in the LC by chronic morphine administration. Extracts of LC from control and chronic (5 d) morphine-treated rats were analyzed for PKA subunits, $\mathrm{Gi} \alpha$, or tyrosine hydroxylase immunoreactivity by Western blotting (see Materials and Methods). The $M_{r}$ values observed for these proteins were PKA catalytic subunit, $41 \mathrm{kDa}$; PKA type I regulatory subunit, $51 \mathrm{kDa}$; PKA type II regulatory subunit, 51 $\mathrm{kDa}$; Gi $\alpha, 41 \mathrm{kDa}$; and tyrosine hydroxylase, $58 \mathrm{kDa}$, which are consistent with published values (see Guitart et al., 1990; Nestler et al., 1990; Nestler and Greengard, 1994). The figure illustrates chronic morphine-induced upregulation of the catalytic and type II regulatory subunits PKA, Gi $\alpha$, and tyrosine hydroxylase and lack of effect of morphine on PKA type I regulatory subunit. These results are shown quantitatively in Table 1.

tide directed against CREB mRNA directly into this brain region (Widnell et al., 1996a). We demonstrated that infusion of this oligonucleotide resulted in a sequence-specific reduction in levels of CREB immunoreactivity, which was not associated with detectable toxicity.

To directly study a role for CREB in opiate action in the LC, we adapted this procedure for this brain region. In initial studies, we demonstrated that infusion of CREB antisense oligonucleotide into the LC unilaterally for $5 \mathrm{~d}$ resulted in a $\sim 20 \%$ reduction in levels of CREB immunoreactivity in the injected LC compared with the uninjected contralateral control side (Fig. 3). This reduction in CREB levels was restricted to the LC: no change in

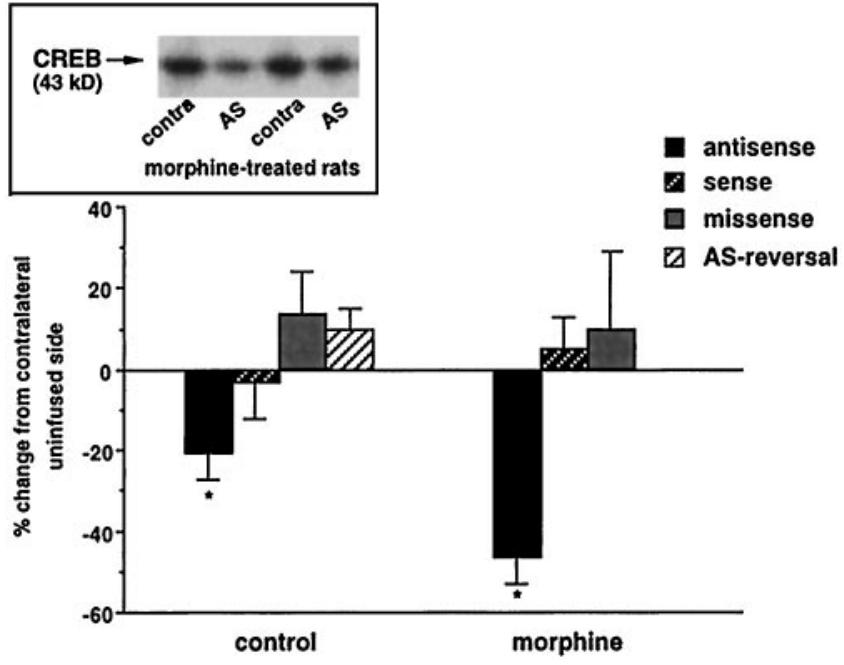

Figure 3. Effect of intra-LC infusion of antisense oligonucleotide to CREB on levels of CREB immunoreactivity. CREB antisense, sense, or missense oligonucleotide (see Materials and Methods) was infused into one LC for $5 \mathrm{~d}$. Some of the rats also received concomitant chronic morphine treatment. In some experiments (AS-reversal), after $5 \mathrm{~d}$ of antisense oligonucleotide infusion, the same LC was infused for 5 additional days with vehicle. After these various treatments, extracts were prepared from the infused and contralateral uninfused LC of each rat. Individual LC extracts were then analyzed for CREB immunoreactivity by Western blotting as described in Materials and Methods. Data are expressed as mean \pm SEM percent change from contralateral uninf used LC $(n=6-12) .{ }^{*} p<0.05$ by $t$ test. Inset, Representative autoradiogram that illustrates the antisense oligonucleotide-induced reduction in CREB immunoreactivity. contra, Contralateral uninfused LC; $A S$, antisense oligonucleotide-inf used LC.

CREB immunoreactivity was seen in a ring of tissue surrounding the LC $(92 \pm 9 \%$ of the contralateral side; $n=6)$. Several lines of evidence indicated that this effect was sequence-specific; $5 \mathrm{~d}$ inf usion of CREB sense oligonucleotide or a missense oligonucleotide (which contained the same GC content as the antisense and sense oligonucleotides) or $5 \mathrm{~d}$ infusion of vehicle failed to alter levels of CREB immunoreactivity compared to the contralateral uninjected LC (Fig. 3). Moreover, the antisense oligonucleotide-induced reduction in CREB levels was not associated with detectable toxicity; the oligonucleotide-infused LC and contralateral uninf used LC were indistinguishable by immunohistochemical staining for tyrosine hydroxylase (Fig. 4) and by Nissl staining (data not shown). Further evidence against toxicity is the finding that the antisense oligonucleotide-induced reduction in CREB levels was fully reversible; $5 \mathrm{~d}$ after cessation of oligonucleotide infusion, levels of CREB immunoreactivity had returned to control levels (Fig. 3).

\section{Regulation of adenylyl cyclase and PKA in the LC on intra-LC infusion of CREB antisense oligonucleotide}

Having established the effectiveness of the CREB antisense oligonucleotide infusion protocol, we examined the effect of such infusions on basal levels of adenylyl cyclase and PKA in the LC. We focused on subtypes or subunits of the enzymes that are regulated by morphine in this brain region (e.g., see Table 1). As shown in Table 2, such infusions elicited small $(\sim 15-25 \%)$ but statistically significant reductions in levels of types VIII and I adenylyl cyclase and of the catalytic and type II regulatory sub- 

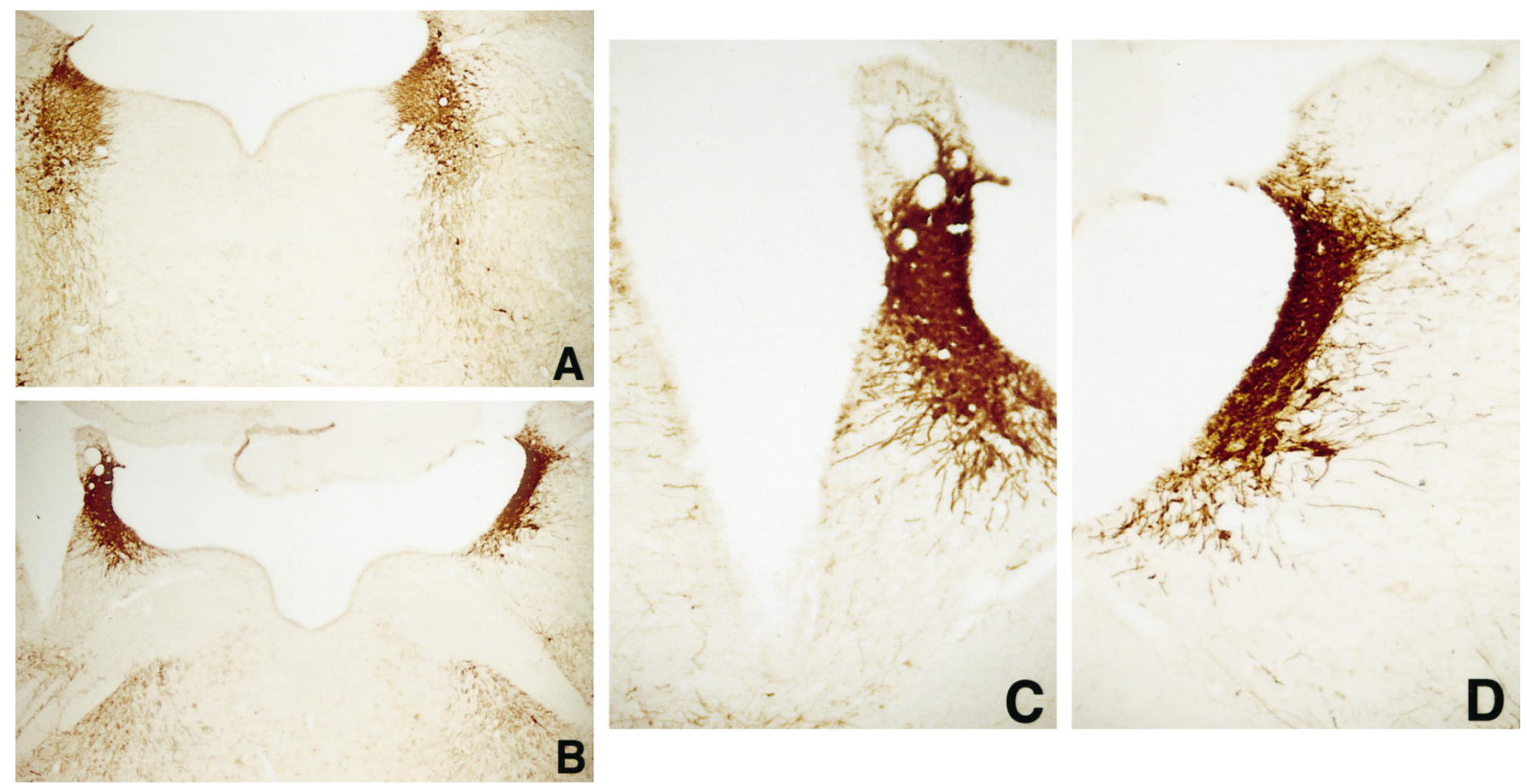

Figure 4. Histological integrity of the LC after CREB antisense oligonucleotide inf usion. CREB antisense oligonucleotide was infused unilaterally just lateral to the LC for $5 \mathrm{~d}$, after which time the effect of the infusion on the integrity of the LC was assessed by immunohistochemical analysis for tyrosine hydroxylase (Materials and Methods). $A, B$, Low-power photomicrographs just rostral to, and at the level of, the infusion cannula, respectively. The injected side is on the left. $C, D$, Higher magnification of the injected and uninjected sides, respectively. As can be seen, the infused LC was indistinguishable from the contralateral uninfused LC. The figure is representative of results obtained from analysis of five rats.

Table 2. Regulation of cAMP pathway proteins in the LC by $5 \mathrm{~d}$ of intra-LC infusion of antisense

oligonucleotide to CREB: effects in drug-naive rats

\begin{tabular}{|c|c|c|c|c|}
\hline & Antisense & Sense & Missense & AS-reversal \\
\hline \multicolumn{5}{|l|}{ Adenylyl cyclase } \\
\hline Type VIII & $73 \pm 7(6)^{*}$ & $104 \pm 7(6)$ & $106 \pm 11(5)$ & \\
\hline Type I & $79 \pm 7(6)^{* *}$ & & & \\
\hline Type III & $95 \pm 8(6)$ & & & \\
\hline \multicolumn{5}{|l|}{ Protein kinase $\mathrm{A}$} \\
\hline Catalytic subunit & $87 \pm 3(11)^{* *}$ & $100 \pm 6(8)$ & $107 \pm 11(6)$ & $103 \pm 15(6)$ \\
\hline Regulatory subunit type II & $85 \pm 3(6)^{* *}$ & $95 \pm 14(6)$ & & \\
\hline $\operatorname{Gi} \alpha$ & $94 \pm 14(6)$ & $97 \pm 12(8)$ & $103 \pm 8(6)$ & $113 \pm 12(6)$ \\
\hline Tyrosine hydroxylase & $82 \pm 3(6)^{*}$ & $102 \pm 11(6)$ & $107 \pm 12(7)$ & $108 \pm 14(6)$ \\
\hline
\end{tabular}

Data are expressed as mean \pm SEM percent of contralateral uninfused side $(n)$. Antisense, sense, and missense refer to intra-LC infusion of antisense, sense, or missense oligonucleotide, respectively. AS-reversal refers to intra-LC inf usion of antisense oligonucleotide for $5 \mathrm{~d}$ followed by $5 \mathrm{~d}$ of vehicle infusion.

${ }^{*} p<0.05 ; * * p \approx 0.1$ by $t$ test.

units of PKA compared with the contralateral uninjected LC. In contrast, no effect was seen on levels of type III adenylyl cyclase, which is not regulated by morphine.

Regulation of types VIII and I adenylyl cyclase and of the PKA subunits by CREB antisense oligonucleotide was sequence-specific; infusion of sense or missense oligonucleotide did not alter levels of immunoreactivity of these proteins in the LC (Table 2). In addition, the antisense oligonucleotide-induced reduction in levels of these proteins was fully reversible, because levels of the proteins returned to control levels $5 \mathrm{~d}$ after cessation of the infusion. The reductions also were restricted to the LC in that they were not observed in a ring of tissue surrounding this brain region (data not shown).

We next studied the ability of intra-LC infusions of CREB antisense oligonucleotide to block the upregulation of adenylyl cyclase and PKA, as well as of CREB itself, produced by chronic morphine treatment. In these experiments, we once again compared levels of the proteins on the infused and uninfused LCs. It was found that after chronic morphine treatment there was $\sim 50 \%$ lower levels of type VIII adenylyl cyclase and of CREB on the antisense oligonucleotide-infused side compared with the contralateral control side (Table 3 ). This reduction was about twice that seen in morphine-naive animals, presumably because the antisense oligonucleotide infusion was not only reducing basal levels of the proteins but also blocking the morphine-induced increase in the proteins that occurs in the contralateral (uninfused) LC. In contrast, levels of the catalytic and regulatory type II subunits of PKA differed by $\sim 15 \%$ between the infused and 


\begin{tabular}{|c|c|c|c|}
\hline & Antisense & Sense & Missense \\
\hline \multicolumn{4}{|l|}{ Adenylyl cyclase } \\
\hline Type VIII & $45 \pm 4(5)^{*}$ & $97 \pm 10(4)$ & $100 \pm 6(6)$ \\
\hline Type I & $107 \pm 6(6)$ & & \\
\hline Type III & $102 \pm 10(6)$ & & \\
\hline \multicolumn{4}{|l|}{ Protein kinase A } \\
\hline $\begin{array}{l}\text { Catalytic subunit } \\
\text { Regulatory subunit }\end{array}$ & $88 \pm 8(12)$ & $95 \pm 2(5)$ & $104 \pm 10(5)$ \\
\hline type II & $86 \pm 12(6)$ & $94 \pm 7(4)$ & \\
\hline $\mathrm{Gi} \alpha$ & $83 \pm 12(12)$ & $104 \pm 10(5)$ & \\
\hline Tyrosine hydroxylase & $54 \pm 8(10)^{*}$ & $102 \pm 2(4)$ & $110 \pm 12(4)$ \\
\hline
\end{tabular}

Data are expressed as mean $\pm \operatorname{SEM}(n)$. Antisense, sense, and missense refer to intra-LC infusion of antisense, sense, or missense oligonucleotide, respectively. ${ }^{*} p<0.05$ by $t$ test.

uninfused sides, similar to the difference observed under morphine-naive conditions (compare Tables 2, 3). These findings suggest that the antisense oligonucleotide inf usions did not block the morphine-induced increase in these proteins. Similar results were obtained with type I adenylyl cyclase. These various effects were not seen with sense or missense oligonucleotide infusion (Table 3). CREB antisense oligonucleotide inf usion had no effect on levels of type III adenylyl cyclase after chronic morphine treatment (Table 3), as found under drug-naive conditions.

Figure 5 shows the results of these various experimental manipulations normalized to levels of the proteins seen under control conditions. As can be seen in the figure, in drug-naive rats, intra-LC infusion of CREB antisense oligonucleotide produced small but significant reductions in levels of CREB itself, types VIII and I adenylyl cyclase, and the catalytic and regulatory type II subunits of PKA. In morphine-treated rats, CREB antisense oligonucleotide infusion completely blocked the morphineinduced increase in CREB and type VIII adenylyl cyclase but did not significantly attenuate the morphine-induced increase in the PKA subunits or in type I adenylyl cyclase.

\section{Regulation of tyrosine hydroxylase and Gi $\alpha$ in the LC on intra-LC infusion of CREB antisense oligonucleotide}

Given the ability of CREB antisense oligonucleotide to block some but not all of the effects of chronic morphine treatment on components of the cAMP pathway in the LC, we examined two other proteins known to be regulated by morphine in this brain region. Previous work demonstrated that chronic morphine treatment increases levels of tyrosine hydroxylase immunoreactivity in the LC (Guitart et al., 1990). This effect was replicated in the present study (Table 1, Fig. 2). It was found further that CREB antisense oligonucleotide infusion significantly decreased basal levels of tyrosine hydroxylase in drug-naive rats and completely blocked the ability of morphine to upregulate the protein (Tables 2, 3, Fig. 5). These effects were not seen with sense or missense oligonucleotide infusion and were fully reversible $5 \mathrm{~d}$ after cessation of antisense oligonucleotide infusion (Tables 2, 3).

Previous studies have shown that chronic morphine treatment increases levels of Gi $\alpha$, as measured by pertussis toxin-catalyzed ADP ribosylation (Nestler et al., 1989). We showed in the present study that this effect is associated with an increase in levels of immunoreactivity of the G-protein subunit, as determined by Western blotting (Table 1, Fig. 2). However, in contrast to several other components of the CAMP pathway, CREB antisense oligonucleotide infusion had no effect on basal levels of Gi $\alpha$ in drugnaive rats, nor did it block upregulation of the protein by chronic morphine administration (Tables 2, 3, Fig. 5). Inf usion of sense or missense oligonucleotide into the LC also had no effect on Gi $\alpha$ immunoreactivity under drug-naive and morphine-treated conditions (Tables 2, 3).

\section{Regulation of LC neuronal activity by intra-LC infusion of CREB antisense oligonucleotide}

To examine the physiological consequences of the CREB antisense oligonucleotide-induced changes in the cAMP pathway in LC neurons, extracellular single-unit recordings were obtained from LC neurons in brain slices from control and morphinetreated rats. The effects of antisense oligonucleotide infusion were studied first in drug-naive rats. It was found that the spontaneous firing rate of LC neurons was reduced by $\sim 50 \%$ in the antisense oligonucleotide-infused LC compared with the contralateral uninfused side (Fig. 6). Such a reduction was not seen after infusion of sense oligonucleotide.

The firing rate of LC neurons is known to be increased by agents that activate the cAMP pathway via activation of a sodium-dependent inward current (Alreja and Aghajanian, 1991, 1993). This is illustrated in Figure 6, which shows that supramaximal concentrations (2 $\mathrm{mM})$ of 8-bromo-cAMP, a membranepermeant analog of cAMP, roughly doubles the spontaneous firing rate of LC neurons. Intra-LC infusion of CREB antisense oligonucleotide reduced the maximal firing rate of LC neurons obtained with 8-bromo-cAMP exposure, an effect not seen with sense oligonucleotide infusions.

As outlined in the introductory remarks, the spontaneous firing rate of LC neurons in brain slices is increased by approximately twofold by previous chronic administration of morphine (Kogan et al., 1992). A similar increase (of $\sim 60 \%$ ) was replicated in the present investigation. Intra-LC inf usion of CREB antisense oligonucleotide reduced the spontaneous firing rate of LC neurons in slices from morphine-treated rats, similar to the effect seen under drug-naive conditions (Fig. 6). This effect was not seen with infusion of sense oligonucleotide. Interestingly, application of 8-bromo-cAMP restored the elevated firing rates of LC neurons in the antisense oligonucleotide-inf used LC to the same values as seen in the contralateral uninfused LC (Fig. 6). This effect of 8-bromo-cAMP was striking given the reduced neuronal firing rates seen under the other experimental conditions. Indeed, this effect of 8-bromo-cAMP provided further strong evidence that reductions in LC firing rates under these other conditions do not reflect toxic effects of the antisense oligonucleotide inf usions but, rather, reflect alterations in selective signal transduction proteins in these neurons.

The ability of 8-bromo-cAMP to restore LC firing rates under chronic morphine-treated conditions suggests that the effect of CREB antisense oligonucleotide infusion is exerted at a step in the cAMP pathway proximal to activation of PKA, perhaps at the level of adenylyl cyclase. This possibility would be consistent with our observation that $\mathrm{CREB}$ antisense oligonucleotide infusion blocked the morphine-induced increase in adenylyl cyclase but not PKA (see Fig. 5). To test this hypothesis, we examined the ability of forskolin (which directly activates adenylyl cyclase) to regulate LC neuronal activity. As shown in Figure 7, forskolin increased the firing rate of LC neurons exposed to CREB anti- 


\section{CREB}

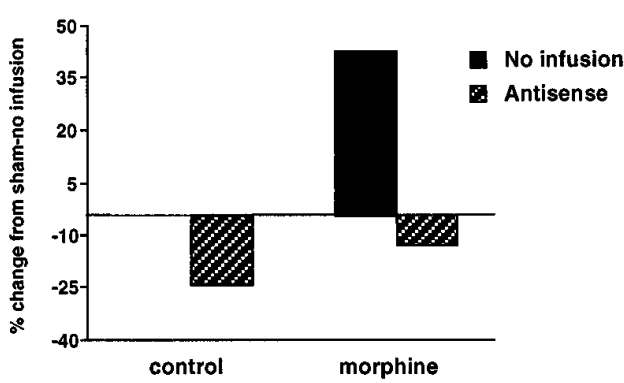

type I adenylyl cyclase

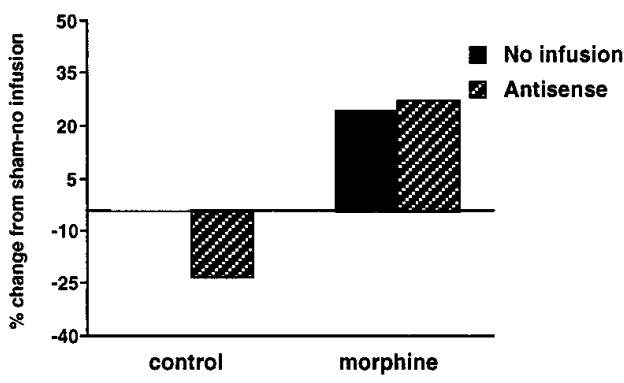

tyrosine hydroxylase

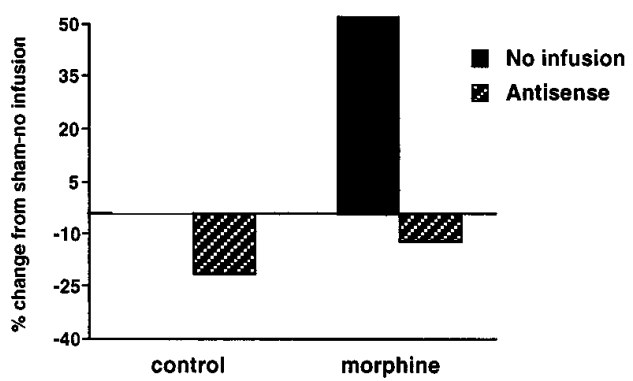

type VIII adenylyl cyclase

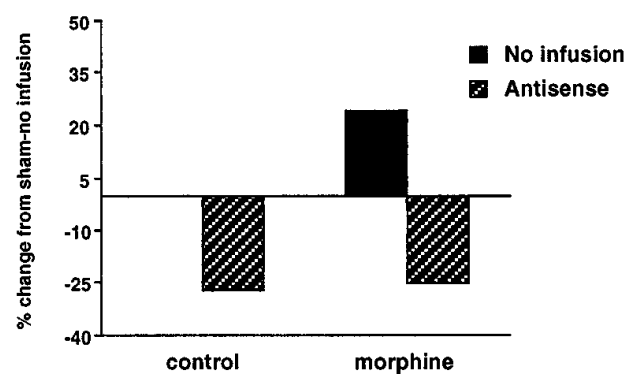

PKA catalytic subunit

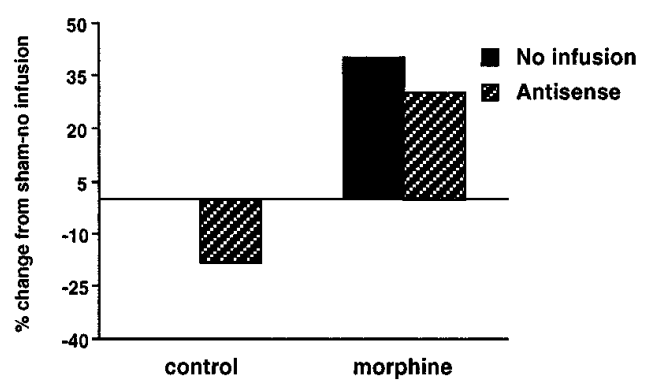

Gi $\alpha$

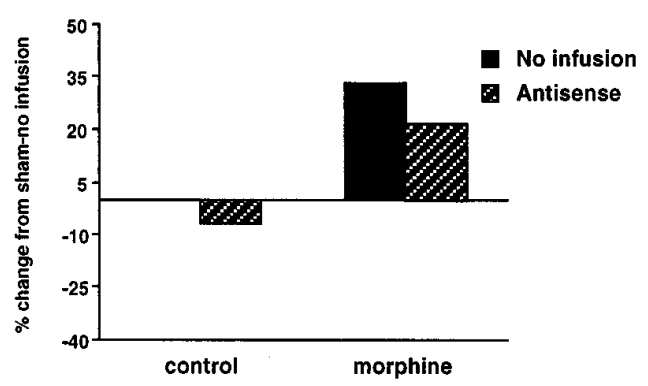

Figure 5. Effect of intra-LC infusion of CREB antisense oligonucleotide on levels of cAMP pathway proteins under control and morphine-treated conditions. Values shown were calculated from data shown in Tables 2 and 3 and Figure 3. Levels of each protein are expressed as percentages of those seen in the LC of control rats (i.e., in the absence of oligonucleotide inf usions and morphine treatment). Regulation of the type II regulatory subunit of PKA was similar to that seen for the catalytic subunit (not shown; see data in Tables 2,3).

sense oligonucleotide under both drug-naive and morphinetreated conditions, but to a much lesser degree than seen for the contralateral uninfused LC neurons. These findings support the possibility, which is consistent with our biochemical data, that the effect of CREB antisense oligonucleotide infusion on LC neurons in chronic morphine-treated rats largely reflects an impaired upregulation of adenylyl cyclase, not PKA.

\section{Regulation of opiate withdrawal by intra-LC infusion of CREB antisense oligonucleotide}

The finding that intra-LC infusion of CREB antisense oligonucleotide impaired the physiological activation of LC neurons produced by chronic morphine treatment raised the expectation that such infusions would reduce the severity of opiate withdrawal, given the importance of the LC in behavioral manifestations of withdrawal (see the introductory remarks). To test this hypothesis directly, withdrawal was precipitated by administration of naltrexone to rats that received bilateral, intra-LC infusions of antisense or sense oligonucleotide to
CREB along with chronic morphine treatment. As shown in Table 4, CREB antisense oligonucleotide inf usion significantly attenuated the appearance of certain withdrawal behaviors, for example, teeth chatter, wet dog shakes, ptosis, vacuous chewing, and irritability, compared with intra-LC infusion of sense oligonucleotide. Attenuation of these behaviors was more marked 16-30 min after precipitation of withdrawal than after 0-15 min. In contrast, certain other withdrawal behaviors (e.g., lacrimation, salivation, piloerection, stereotypy, and diarrhea) were not affected. Antisense oligonucleotide infusions also did not affect weight loss during the first hour of withdrawal (data not shown). Similar results were obtained with unilateral oligonucleotide infusions, although the attenuation in withdrawal behaviors after unilateral antisense oligonucleotide infusions was smaller in magnitude compared with that seen after bilateral infusions (data not shown). The severity of withdrawal behaviors observed in rats after sense oligonucleotide infusions was equivalent to results obtained after vehicle inf usions (data not shown). 
SHAM

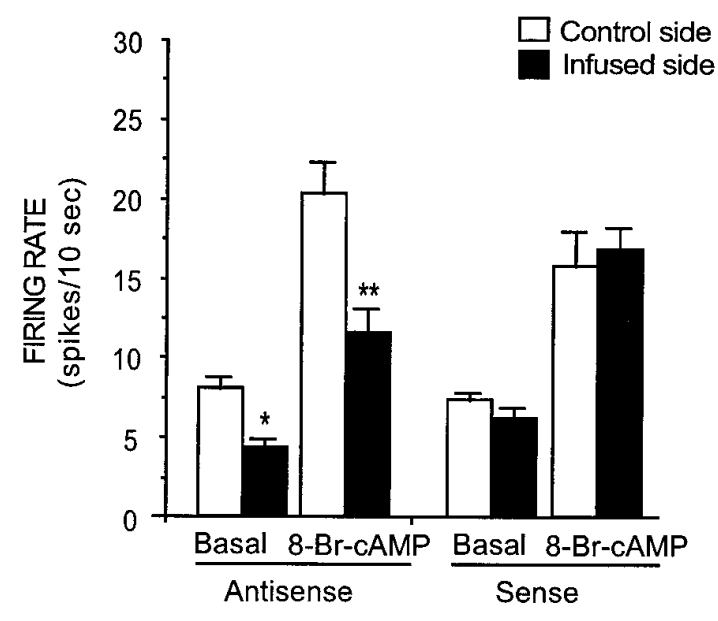

MORPHINE

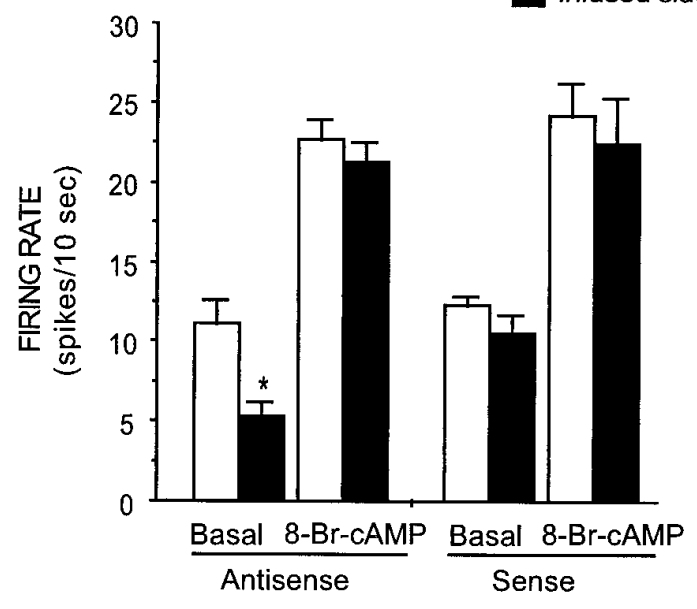

Figure 6. Effect of intra-LC inf usion of CREB antisense oligonucleotide on firing rates of LC neurons: activation by 8-bromo-cAMP. CREB antisense or sense oligonucleotide (see Materials and Methods) was infused into one LC for $5 \mathrm{~d}$. The rats also received chronic sham or morphine treatment (on days 2-5). After these treatments, extracellular single-unit recordings were obtained from LC neurons in brain slices on the inf used side and on the contralateral uninf used side. Recordings were obtained under basal conditions and after bath application of 8-bromocAMP $(2 \mathrm{mM})$. Data are expressed as mean \pm SEM firing rates and represent results obtained from five or six animals ( $\sim 50-60$ neurons) in each treatment group. In sham-treated animals, CREB antisense oligonucleotide significantly reduced both the basal firing rate of LC neurons and their activation by 8-bromo-cAMP. In chronic morphine-treated animals, there was again a reduction in basal firing rates, which was completed reversed by 8 -bromo-cAMP. ${ }^{*} p<0.05$ by $t$ test compared with control side; ${ }^{* *} p<0.001$.

\section{DISCUSSION}

The results of the present study add to our knowledge of the molecular mechanisms by which chronic exposure to opiates leads to dependence at a cellular level in LC neurons. We show that chronic morphine administration increases levels of specific subtypes of adenylyl cyclase and of specific subunits of PKA in the LC. Using an antisense oligonucleotide strategy, we show further that the upregulation of adenylyl cyclase, but not that of PKA, requires CREB. This differential regulation of adenylyl cyclase
SHAM

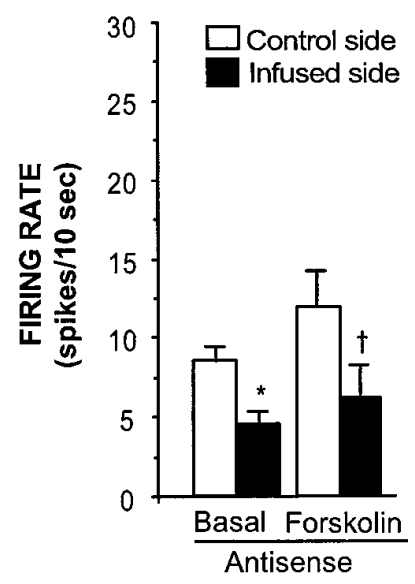

MORPHINE

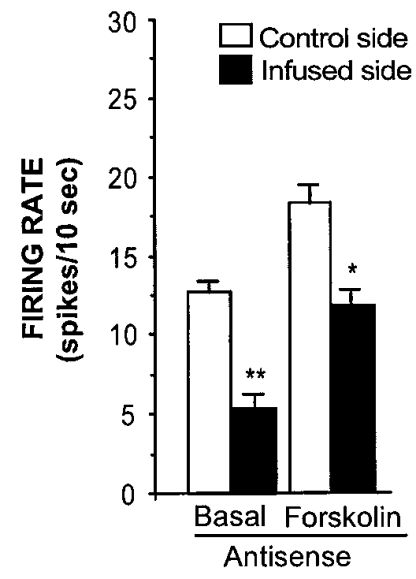

Figure 7. Effect of intra-LC inf usion of CREB antisense oligonucleotide on firing rates of LC neurons: activation by forskolin. CREB antisense or sense oligonucleotide was infused into one LC for $5 \mathrm{~d}$ in sham- and morphine-treated animals, as described in the legend to Figure 6. Extracellular single-unit recordings were then obtained from LC neurons on the infused side and on the contralateral uninfused side in brain slices under basal conditions and after bath application of forskolin $(10 \mu \mathrm{M})$. Data are expressed as mean \pm SEM firing rates and represent results obtained from five or six animals ( $\sim 50-60$ neurons) in each treatment group. In sham-treated animals, CREB antisense oligonucleotide significantly reduced the basal firing rate of LC neurons (replicating the result shown in Fig. 6) and also reduced activation of the neurons by forskolin, as seen with 8-bromo-cAMP (Fig. 6). However, in chronic morphinetreated animals, the reduction in basal firing rates was only partially reversed by forskolin, in contrast to the complete reversal seen with 8-bromo-cAMP. ${ }^{*} p<0.05$ by $t$ test compared with control side; ${ }^{*} p<$ $0.005,{ }^{\dagger} p=0.087$.

and PKA by CREB, demonstrated at the biochemical level, was also observed at the electrophysiological level based on measurements of LC neuronal firing rates. Finally, we show that antisense oligonucleotide blockade of CREB, and its consequent effects on specific cAMP pathway proteins, reduces the degree of opiate dependence in LC neurons, based on attenuation of the severity of opiate withdrawal behaviors elicited by administration of naltrexone. Together, these results provide the first direct evidence for a role of CREB in the development of opiate dependence in the LC and identify specific target proteins through which these behavioral actions of CREB could be mediated.

Previously, chronic exposure to morphine was shown to increase levels of adenylyl cyclase catalytic activity in the LC (Duman et al., 1988). Although Matsuoka et al. (1994) reported that chronic morphine treatment increases levels of type VIII adenylyl cyclase mRNA in the LC, other types of the enzyme have not been examined. Thus, in the initial phase of the present study, we characterized which of the many known forms of adenylyl cyclase are expressed in the LC and, of those that are, which are regulated in this brain region by chronic morphine administration. We found that types VIII and I are upregulated by chronic exposure to morphine, whereas several other types are not affected. It is interesting to note that these forms of adenylyl cyclase share key regulatory properties: both are activated by $\mathrm{Ca}^{2+}$ and are only mildly activated by Gs $\alpha$ (Cooper et al., 1995; Sunahara et al., 1995). The type I enzyme also is inhibited by G-protein $\beta \gamma$ subunits, although it remains unknown whether the type VIII enzyme is similarly regulated. Thus, chronic morphine exposure selectively upregulates $\mathrm{Ca}^{2+}$-sensitive forms of adenylyl 
Table 4. Regulation of opiate withdrawal by $5 \mathrm{~d}$ of intra-LC infusion of antisense oligonucleotide to CREB

Severity of withdrawal behavior

\begin{tabular}{lccccc} 
& \multicolumn{2}{c}{ Sense-treated } & & \multicolumn{2}{l}{ Antisense-treated } \\
\cline { 2 - 3 } \cline { 5 - 6 } & $0-15 \mathrm{~min}$ & $16-30 \mathrm{~min}$ & & $0-15 \mathrm{~min}$ & $16-30 \mathrm{~min}$ \\
\hline Behaviors attenuated by CREB & antisense oligonucleotide & \\
Teeth chatter & $2.2 \pm 0.3$ & $1.7 \pm 0.4$ & $2.4 \pm 0.4$ & $0.3 \pm 0.2^{* *}$ \\
Wet dog shakes & $2.8 \pm 0.3$ & $1.2 \pm 0.3$ & $2.2 \pm 0.2^{*}$ & $0.7 \pm 0.2^{* *}$ \\
Ptosis & $1.4 \pm 0.2$ & $1.8 \pm 0.2$ & $1.1 \pm 0.1$ & $1.1 \pm 0.2^{* *}$ \\
Irritability & $1.3 \pm 0.2$ & $1.8 \pm 0.2$ & $0.9 \pm 0.2^{*}$ & $0.7 \pm 0.2^{* *}$ \\
Vacuous chewing & $1.6 \pm 0.3$ & $1.4 \pm 0.4$ & $1.3 \pm 0.2$ & $0.7 \pm 0.2^{* *}$ \\
Behaviors not affected by CREB antisense oligonucleotide & \\
Piloerection & $1.3 \pm 0.2$ & $1.1 \pm 0.4$ & $1.3 \pm 0.3$ & $1.3 \pm 0.2$ \\
Lacrimation & $0.5 \pm 0.2$ & $0.8 \pm 0.1$ & $0.8 \pm 0.3$ & $0.8 \pm 0.1$ \\
Salivation & 0 & $0.5 \pm 0.3$ & 0 & $0.5 \pm 0.4$ \\
Diarrhea & $1.2 \pm 0.4$ & $1.5 \pm 0.4$ & $0.9 \pm 0.3$ & $1.2 \pm 0.4$ \\
Stereotypy & $0.7 \pm 0.3$ & 0 & $0.9 \pm 0.5$ & 0 \\
\hline
\end{tabular}

Rats received bilateral intra-LC infusions of antisense or sense oligonucleotide to CREB and were then treated chronically with morphine (see Materials and Methods). Withdrawal was precipitated by administration of naltrexone $(10 \mathrm{mg} / \mathrm{kg}$, s.c.) Withdrawal behaviors were scored from 0 to 3 as described in Materials and Methods. No withdrawal behaviors were observed in rats before administration of naltrexone (data not shown). Data are expressed as mean \pm SEM $(n=6$ in each group).

${ }^{*} p<0.1 ;{ }^{* *} p<0.05$ by $t$ test.

cyclase. Further work is needed to understand the physiological significance of this phenomenon better.

Our original study of PKA demonstrated an increase in enzyme catalytic activity in the LC after chronic morphine administration (Nestler and Tallman, 1988). The results of the present study extend these findings by showing that increased PKA activity is associated with increased levels of immunoreactivity of the catalytic and type II regulatory subunits of the enzyme, with no change in levels of the type I regulatory subunit. This is interesting because the type II regulatory subunit is thought to be more highly enriched in neurons compared with the type I subunit (see Nestler and Greengard, 1994). Each PKA subunit exists as two isoforms, termed $\alpha$ and $\beta$, which are encoded by distinct genes (Cadd and McKnight, 1989). Unfortunately, we were unable to distinguish these isoforms by Western blotting, which is not surprising, because in rodent the two forms differ by only one or two amino acids in the immunizing peptides. Thus, it remains unknown whether the increased levels of catalytic and type II regulatory subunits seen after morphine treatment reside in the $\alpha$ or $\beta$ isoforms of these proteins.

Based on earlier studies of other brain regions (Konradi et al., 1994; Widnell et al., 1996a), we show here that intra-LC infusion of CREB antisense oligonucleotide results in a sequence-specific reduction in levels of CREB immunoreactivity that is circumscribed to the LC and is not associated with detectable toxicity. Thus, the reduction was not elicited by infusion of sense or missense oligonucleotide; the antisense oligonucleotide effect, which was not seen in a ring of tissue immediately surrounding the LC, was fully reversible within $5 \mathrm{~d}$ of cessation of the inf usion, and the antisense oligonucleotide-infused LC was histologically normal. These results demonstrate that, although rigorous criteria must be followed to ensure efficacy and lack of toxicity (see Russell et al., 1996), antisense oligonucleotides can be used to reduce selectively, in specific brain regions, levels of a protein (e.g., CREB) for which there is no traditional pharmacological antagonist.

The results of the present study show clear differences among components of the cAMP pathway with respect to regulation of their expression by CREB. Type VIII adenylyl cyclase and tyrosine hydroxylase were the most dramatically controlled by CREB; CREB antisense oligonucleotide infusions reduced basal levels of the proteins in the LC and completely prevented their upregulation by chronic morphine administration. The morphineinduced upregulation of CREB itself was similarly prevented. In contrast, levels of PKA subunits and type I adenylyl cyclase were only slightly reduced by CREB antisense oligonucleotide under basal conditions, and their upregulation by chronic morphine treatment was unaffected, whereas levels of Gi $\alpha$ were not altered under basal or morphine-treated conditions. Although some of the changes observed in response to antisense oligonucleotide treatment are relatively small in magnitude, such changes would be expected to exert important physiological consequences attributable to the extraordinary amplification of intracellular messenger pathways. For example, a $15 \%$ reduction in Gi $\alpha$ function has been shown to result in a $50 \%$ decrement in physiological response, whereas a $50 \%$ reduction results in a complete loss of physiological response (Innis et al., 1988). Similarly, a 20-30\% change in PKA activity has been shown to result in significant changes in the state of phosphorylation of specific phosphoproteins (Guitart and Nestler, 1989; Guitart et al., 1990, 1992).

The differential regulation of components of the cAMP pathway by CREB in the LC provides new insight on the molecular mechanisms through which expression of these various signaling proteins is regulated in this brain region in vivo. Tyrosine hydroxylase provides a useful point of reference, because the promoter of its gene is well characterized. CREB, acting at a CRE within the tyrosine hydroxylase promoter, has been shown to play a critical role in basal activity of the promoter as well as its induction under several experimental conditions in cell culture (Kim et al., 1993; Lazaroff et al., 1995). These in vitro results are consistent with the present findings in vivo. Type VIII adenylyl cyclase appears to be regulated in a similar manner, although the promoter of its gene has not yet been isolated. In contrast, different molecular mechanisms would appear to operate for PKA subunits, type I adenylyl cyclase, and Gi $\alpha$. Indeed, functional CREs have not been found to date in the promoters of the genes for these proteins (GenBank). More complete characterization of these promoters may provide leads concerning the mechanisms by which PKA subunits, adenylyl cyclase type I, and Gi $\alpha$ are upregulated in the LC by chronic morphine administration.

The differential regulation of cAMP pathway proteins by CREB appears to account for the electrophysiological effects of CREB antisense oligonucleotide inf usions on LC neurons. Under basal conditions, it is known that the spontaneous firing rate of LC neurons in brain slices depends in part on the activity of the cAMP pathway. Levels of PKA would appear to be limiting, because even small reductions in the enzyme elicited by CREB antisense oligonucleotide inf usions reduced the firing rate of LC neurons and their maximal response to 8-bromo-cAMP. More complicated effects were seen under morphine-treated conditions: reduced spontaneous firing rate of LC neurons, and the restoration of LC firing rates with 8-bromo-cAMP but not forskolin. These observations are consistent with the observation that chronic morphine treatment increases levels of PKA even in the presence of CREB antisense oligonucleotide, whereas upregulation of adenylyl cyclase is attenuated. Under these conditions, 
levels of adenylyl cyclase would appear to be the limiting factor for the enhanced physiological activity of LC neurons.

A recent study demonstrated that mice deficient in CREB show attenuated development of opiate physical dependence (Maldonado et al., 1996). However, this deficiency in CREB occurs throughout the brain and peripheral tissues as well. The present study, therefore, extends this earlier observation by showing that the LC is one critical brain region where CREB acts to reduce opiate dependence and by revealing specific target genes (e.g., type VIII adenylyl cyclase and tyrosine hydroxylase) through which CREB may produce this effect.

One critical question now is what the mechanism is by which morphine regulates CREB to produce these various actions. As stated in the introductory remarks, chronic morphine treatment increases levels of CREB expression and phosphorylation in the LC (Guitart et al., 1992; Widnell et al., 1994). Recently, we have shown in Cath.a cells (an LC-like cell line) that activation of the cAMP pathway decreases CREB gene transcription (Widnell et al., 1996b) possibly through CREs contained within the CREB promoter (Coven et al., 1996). Thus, one possibility is that persistent inhibition of the cAMP pathway in the LC by morphine leads to upregulation of CREB transcription and, subsequently, to upregulation of type VIII adenylyl cyclase and tyrosine hydroxylase. Although the present study shows that CREB is necessary for upregulation of these two putative target genes, further work will be needed to show that upregulation of CREB is also sufficient to elicit these adaptations.

Together, results from the present study highlight the increasing ability to relate molecular adaptations in the brain to altered physiological function of the particular neurons involved and to important behavioral manifestations of such alterations in neuronal activity. These types of studies will provide a gradually more complete understanding of the molecular and cellular mechanisms underlying the long-term changes produced in the brain by drugs of abuse that lead to a state of addiction.

\section{REFERENCES}

Aghajanian GK (1978) Tolerance to locus coeruleus neurons to morphine and suppression of withdrawal response by clonidine. Nature 267:186-188.

Akaoka H, Aston-Jones G (1991) Opiate withdrawal-induced hyperactivity of locus coeruleus neurons is substantially mediated by augmented excitatory amino acid input. J Neurosci 11:3830-3839.

Alreja M, Aghajanian GK (1991) Pacemaker activity of locus coeruleus neurons: whole-cell recordings in brain slices show dependence on cAMP and protein kinase A. Brain Res 556:339-343.

Alreja M, Aghajanian GK (1993) Opiates suppress a resting sodiumdependent inward current in addition to activating an outward potassium current locus coeruleus neurons. J Neurosci 13:3525-3532.

Aston-Jones G, Rajkowski J, Kubiak P, Valentino RJ, Shipley MT (1996) Role of the locus coeruleus in emotional activation. Prog Brain Res 107:379-402.

Berhow MT, Hiroi N, Nestler EJ (1996) Regulation of ERK (extracellular signal regulated kinase), part of the neurotrophin signal transduction cascade, in the rat mesolimbic dopamine system by chronic exposure to morphine or cocaine. J Neurosci 16:4707-4715.

Cadd G, McKnight GS (1989) Distinct patterns of cAMP-dependent protein kinase gene expression in mouse brain. Neuron 3:71-79.

Cali JJ, Zwaagstra JC, Mons N, Cooper DM, Krupinski J (1994) Type VIII adenylyl cyclase. A $\mathrm{Ca}^{2+} /$ calmodulin-stimulated enzyme expressed in discrete regions of rat brain. J Biol Chem 269:12190-12195.

Cali JJ, Parekh RS, Krupinski J (1996) Splice variants of type VIII adenylyl cyclase. Differences in glycosylation and regulation by $\mathrm{Ca}^{2+}$ / calmodulin. J Biol Chem 271:1089-1095.

Christie MJ, Williams JT, Osborne PB, Bellchambers CE (1997) Where is the locus in opioid withdrawal? Trends Neurosci 18:134-140.

Cooper DMF, Mons N, Karpen JW (1995) Adenylyl cyclases and the interaction between calcium and cAMP signalling. Nature 374:421-424.

Coven ER, Widnell KL, Chen JS, Walker WH, Habener JF, Nestler EJ (1996) Molecular mechanisms in the cellular specificity of CREB expression. Soc Neurosci Abstr 22:382.

Dahlstrom A, Fuxe K (1965) Evidence for the existence of monoaminecontaining neurons in the central nervous system. I. Demonstration of monoamines in the cell bodies of brain stem neurons. Acta Physiol Scad 62[Suppl 232]:1-55.

Duman RS, Tallman JF, Nestler EJ (1988) Acute and chronic opiate regulation of adenylate cyclase in brain: specific effects in locus coeruleus. J Pharmacol Exp Ther 246:1033-1039.

Fitzgerald LW, Ortiz J, Hamedani AG, Nestler EJ (1996) Regulation of glutamate receptor subunit expression by drugs of abuse and stress: common adaptations among cross-sensitizing agents. J Neurosci 16:274-282.

Foote SL, Bloom FE, Aston-Jones G (1983) Nucleus locus ceruleus: new evidence of anatomical and physiological specificity. Physiol Rev 63:844-914.

Furuyama T, Inagaki S, Takagi H (1993) Distribution of type II adenylyl cyclase mRNA in rat brain. Mol Brain Res 19:165-170.

Glatt CF, Snyder SH (1993) Cloning and expression of an adenylyl cyclase localized to the corpus striatum. Nature 361:536-538.

Guitart X, Nestler EJ (1989) Identification of morphine- and cyclic AMP-regulated phosphoproteins (MARPPs) in the locus coeruleus and other regions of rat brain: regulation by acute and chronic morphine. J Neurosci 9:4371-4387.

Guitart X, Hayward M, Nisenbaum LK, Beitner DB, Haycock JW, Nestler EJ (1990) Identification of MARPP-58, a morphine- and cyclic AMP-regulated phosphoprotein of $58 \mathrm{kDa}$, as tyrosine hydroxylase: evidence for regulation of its expression by chronic morphine in the rat locus coeruleus. J Neurosci 10:2635-2645.

Guitart X, Thompson MA, Mirante CK, Greenberg ME, Nestler EJ (1992) Regulation of CREB phosphorylation by acute and chronic morphine in the rat locus coeruleus. J Neurochem 58:1168-1171.

Guitart X, Kogan JH, Berhow M, Terwilliger RZ, Aghajanian GK, Nestler EJ (1993) Lewis and Fischer rat strains display differences in biochemical, electrophysiol-ogical, and behavioral parameters: studies in the nucleus accumbens and locus coeruleus of drug naive and morphine-treated animals. Brain Res 611:7-17.

Hellevuo K, Yoshimura M, Mons N, Hoffman PL, Cooper DMF, Tabakoff B (1995) The characterization of a novel form of adenylyl cyclase which is present in brain and other tissues. $J$ Biol Chem 270:11581-11589.

Innis RB, Nestler EJ, Aghajanian GK (1988) Evidence of G-protein mediation of serotonin- and $\mathrm{GABA}_{\mathrm{B}}$-induced hyperpolarization of rat dorsal raphe neurons. Brain Res 459:27-36.

Kim KS, Park DH, Wessel TC, Song B, Wagner JA, Joh TH (1993) A dual role for the cAMP-dependent protein kinase in tyrosine hydroxylase gene expression. Proc Natl Acad Sci USA 90:3471-3475.

Kogan JH, Nestler EJ, Aghajanian GK (1992) Elevated basal firing rates of locus coeruleus neurons in brain slices from opiate-dependent rats: association with enhanced responses to 8-Br-cAMP. Eur J Pharmacol 211:47-53.

Konradi C, Cole RL, Heckers S, Hyman SE (1994) Amphetamine regulates gene expression in rat striatum via transcription factor CREB. J Neurosci 14:5623-5634.

Koob GF, Maldonado R, Stinus L (1992) Neural substrates of opiate withdrawal. Trends Neurosci 15:186-191.

Lane SB, Pineda J, Boundy VA, Widnell KL, Aghajanian GK, Nestler EJ (1996) Role of CREB in chronic morphine-induced adaptations in locus coeruleus neurons. Soc Neurosci Abstr 22:382.

Lazaroff M, Patankar S, Yoon SO, Chikaraishi DM (1995) The cyclic AMP response element directs tyrosine hydroxylase expression in catecholaminergic central and peripheral nervous system cell lines from transgenic mice. J Biol Chem 270:21579-21589.

Maldonado R, Koob GF (1993) Destruction of the locus coeruleus decreases physical signs of opiate withdrawal. Brain Res 605:128-138.

Maldonado R, Valverde O, Garbay C, Roques BP (1995) Protein kinases in the locus coeruleus and periaqueductal gray matter are involved in the expression of opiate withdrawal. Naunyn Schmiedebergs Arch Pharmacol 352:565-575.

Maldonado R, Blendy JA, Tzavara E, Gass P, Roques BP, Hanoune J (1996) Reduction of morphine abstinence in mice with a mutation in the gene encoding CREB. Science 273:657-659. 
Matsuoka I, Maldonado R, Defer N, Noel F, Hanoune J, Roques BP (1994) Chronic morphine administration causes region-specific increase of brain type VIII adenylyl cyclase mRNA. Eur J Pharmacol 268:215-221.

Nestler EJ (1992) Molecular mechanisms of drug addiction. J Neurosci $12: 2439-2450$.

Nestler EJ (1996) Under seige: the brain on opiates. Neuron 16:897-900

Nestler EJ, Greengard P (1994) Protein phosphorylation and the regulation of neuronal function. In: Basic neurochemistry: molecular, cellular, and medical aspects, Ed 5 (Siegel GJ, Albers RW, Agranoff BW, Molinoff P, eds), pp 449-474. Boston: Little, Brown.

Nestler EJ, Tallman JF (1988) Chronic morphine treatment increases cyclic AMP-dependent protein kinase activity in the rat locus coeruleus. Mol Pharmacol 33:127-132.

Nestler EJ, Erdos JJ, Terwilliger R, Duman RS, Tallman JF (1989) Regulation of G-proteins by chronic morphine in the rat locus coeruleus. Brain Res 476:230-239.

Nestler EJ, Terwilliger RZ, Walker J, Sevarino KA, Duman RS (1990) Chronic cocaine decreases levels of the G-protein subunits Gi $\alpha$ and Go $\alpha$ in discrete regions of rat brain. J Neurochem 55:1079-1082.

Nestler EJ, Hope BT, Widnell KL (1993) Drug addiction: a model for the molecular basis of neural plasticity. Neuron 11:995-1006.

Paxinos G, Watson C (1982) The rat brain in stereotaxic coordinates. New York: Academic.

Punch L, Self DW, Nestler EJ, Taylor JR (1997) Opposite modulation of opiate withdrawal behaviors upon microinfusion of a protein kinase A inhibitor versus activator into the locus coeruleus or periaqueductal gray. J Neurosci, in press.

Rasmussen K, Aghajanian GK (1989) Withdrawal-induced activation of locus coeruleus neurons in opiate-dependent rats: attenuation by lesions of the nucleus paragigantocellularis. Brain Res 505:346-350.

Rasmussen K, Beitner-Johnson DB, Krystal JH, Aghajanian GK, Nestler EJ (1990) Opiate withdrawal and the rat locus coeruleus: Behavioral, electrophysiological, and biochemical correlates. J Neurosci 10:2308-2317.

Russell DS, Widnell KL, Nestler EJ (1996) Antisense oligonucleotides: New tools for the study of brain function. Neuroscientist 2:79-82.

Sunahara RK, Dessauer CW, Gilman AG (1995) Complexity and diversity of mammalian adenylyl cyclases. Annu Rev Pharmacol Toxicol 36:461-480.

Wallach J, Droste M, Kluxen FW, Pfeuffer T, Frank R (1994) Molecular cloning and expression of a novel type $\mathrm{V}$ adenylyl cyclase from rabbit myocardium. FEBS Lett 338:257-263.

Widnell KL, Russell D, Nestler EJ (1994) Regulation of cAMP response element binding protein in the locus coeruleus in vivo and in a locus coeruleus-like (CATH.a) cell line in vitro. Proc Natl Acad Sci USA 91:10947-10951.

Widnell KL, Self DW, Lane SB, Russell DS, Vaidya V, Miserendino MJD, Rubin CS, Duman RS, Nestler EJ (1996a) Regulation of CREB expression: in vivo evidence for a functional role in morphine action in the nucleus accumbens. J Pharmacol Exp Ther 276:306-315.

Widnell KL, Chen J-S, Iredale PA, Walker WH, Duman RS, Habener JF, Nestler EJ (1996b) Transcriptional regulation of CREB (cAMP response element-binding protein) expression in CATH.a cells. J Neurochem 66:1770-1773.

Xia Z, Choi E-J, Wang F, Blazynski C, Storm DR (1993) Type I calmodulin-sensitive adenylyl cyclase is neural specific. J Neurochem 60:305-311. 